\title{
Front Matter: Volume 10766
}

, "Front Matter: Volume 10766," Proc. SPIE 10766, Infrared Sensors, Devices, and Applications VIII, 1076601 (14 November 2018); doi: 10.1117/12.2516331

SPIE Event: SPIE Optical Engineering + Applications, 2018, San Diego, California, SPIE. United States 


\section{PROCEEDINGS OF SPIE}

\section{Infrared Sensors, Devices, and Applications VIII}

Paul D. LeVan

Priyalal Wijewarnasuriya

Arvind I. D'Souza

Editors

22-23 August 2018

San Diego, California, United States

Sponsored and Published by

SPIE

Volume 10766 
The papers in this volume were part of the technical conference cited on the cover and title page. Papers were selected and subject to review by the editors and conference program committee. Some conference presentations may not be available for publication. Additional papers and presentation recordings may be available online in the SPIE Digital Library at SPIEDigitalLibrary.org.

The papers reflect the work and thoughts of the authors and are published herein as submitted. The publisher is not responsible for the validity of the information or for any outcomes resulting from reliance thereon.

Please use the following format to cite material from these proceedings:

Author(s), "Title of Paper," in Infrared Sensors, Devices, and Applications VIII, edited by Paul D. LeVan, Priyalal Wijewarnasuriya, Arvind I. D'Souza, Proceedings of SPIE Vol. 10766 (SPIE, Bellingham, WA, 2018) Seven-digit Article CID Number.

ISSN: 0277-786X

ISSN: 1996-756X (electronic)

ISBN: 9781510621039

ISBN: 9781510621046 (electronic)

Published by

SPIE

P.O. Box 10, Bellingham, Washington 98227-0010 USA

Telephone +1 3606763290 (Pacific Time) · Fax +1 3606471445

SPIE.org

Copyright (C) 2018, Society of Photo-Optical Instrumentation Engineers.

Copying of material in this book for internal or personal use, or for the internal or personal use of specific clients, beyond the fair use provisions granted by the U.S. Copyright Law is authorized by SPIE subject to payment of copying fees. The Transactional Reporting Service base fee for this volume is $\$ 18.00$ per article (or portion thereof), which should be paid directly to the Copyright Clearance Center (CCC), 222 Rosewood Drive, Danvers, MA 01923. Payment may also be made electronically through CCC Online at copyright.com. Other copying for republication, resale, advertising or promotion, or any form of systematic or multiple reproduction of any material in this book is prohibited except with permission in writing from the publisher. The CCC fee code is 0277$786 \mathrm{X} / 18 / \$ 18.00$.

Printed in the United States of America.

Publication of record for individual papers is online in the SPIE Digital Library.

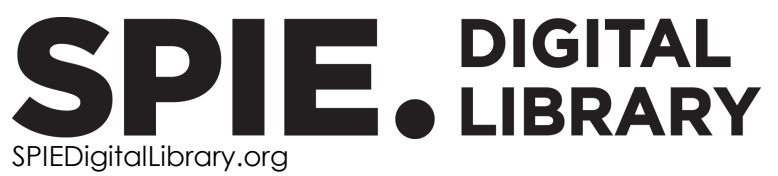

Paper Numbering: Proceedings of SPIE follow an e-First publication model. A unique citation identifier (CID) number is assigned to each article at the time of publication. Utilization of CIDs allows articles to be fully citable as soon as they are published online, and connects the same identifier to all online and print versions of the publication. SPIE uses a seven-digit CID article numbering system structured as follows:

- The first five digits correspond to the SPIE volume number.

- The last two digits indicate publication order within the volume using a Base 36 numbering system employing both numerals and letters. These two-number sets start with $00,01,02,03,04$, 05, 06, 07, 08, 09, 0A, OB ... 0Z, followed by 10-1Z, 20-2Z, etc. The CID Number appears on each page of the manuscript. 


\title{
Contents
}

\author{
$\checkmark \quad$ Authors \\ vii Conference Committee \\ ix Introduction
}

SESSION 1 IR SENSORS, DEVICES, AND APPLICATIONS: DETECTOR THEORY, MODELS, AND SIMULATIONS

1076603 Microscopic theory for point-defect effects on photon absorption in quantum-well systems [10766-2]

1076604 Atomic-level based non-ionizing energy loss: an application to GaAs and GaN semiconductor materials [10766-3]

\section{SESSION 2 NOVEL DETECTORS AND MATERIALS}

1076605 A systematic study of resonator quantum well infrared photodetector (QWIP) [10766-5]

1076606 Sensitive uncooled thermal imager based on liquid crystal Fabry-Perot interferometer [10766-7]

1076607 High-operating temperatures InAsSb/AISb heterostructure infrared detectors [10766-8]

1076609 Development of high performance ultraviolet and near-infrared detector technologies [10766-10]

\section{SESSION $3 \quad$ CHARACTERIZATION AND NOVEL PIXEL PROCESSING}

10766 OD Electrical and optical characterization of $\mathrm{Al}_{\mathbf{x}} \mathrm{N}_{\mathbf{y}}$ thin films [10766-14]

10766 OE High operating temperature MCT discrete detector data and analysis [10766-15]

10766 OF Tunable mid-infrared optical resonator on nanopatterned chalcogenide glasses [10766-35] 
$10766 \mathrm{OH} \quad$ Review of the development of 2k2 IR FPAs for astronomy and Space in Europe [10766-17]

10766 Ol Nanostructured antireflection coatings for infrared sensors and applications [10766-18]

10766 OJ High performance SWIR HgCdTe $320 \times 256 / 30 \mu m$ FPAs at Teledyne Judson Technologies [10766-34]

\section{SESSION 5 EO/IR COMPONENTS AND APPLICATIONS}

10766 OK High through-put outdoor characterization of silicon photovoltaic modules by moving electroluminescence measurements [10766-19]

10766 OL Study on mid-IR spectroscopy on whole blood samples for human glucose quantification applications [10766-20]

10766 OM Anomalous thermal expansion of mercurous halides [10766-21]

10766 ON Polarimetric hyperspectral imaging with acousto-optic tunable filter in the visible to shortwave infrared range [10766-22]

\section{SESSION 6 INNOVATIVE EO FIBER APPLICATIONS}

10766 OP Design of a Fabry-Perot interferometer based on silicon wafer for dielectric gas sensing applications [10766-27]

$107660 Q \quad$ Fiber optic transverse pressure detection technology for structural health monitoring [10766-28]

\section{POSTER SESSION}

$10766 \mathrm{OR} \quad \mathrm{Hg}_{3} \mathrm{In}_{2} \mathrm{Te}_{6}$-based radiation and temperature stable photodetectors [10766-4]

10766 OS A model of measurement error caused by non-uniform spot on four-quadrant detector [10766-30]

10766 OT Error correction model based on echo power in pulsed laser ranging system [10766-31]

10766 OV Spectral vision system for discriminating small pelagic species caught by small-scale fishing [10766-33] 


\title{
Authors
}

Numbers in the index correspond to the last two digits of the seven-digit citation identifier (CID) article numbering system used in Proceedings of SPIE. The first five digits reflect the volume number. Base 36 numbering is employed for the last two digits and indicates the order of articles within the volume. Numbers start with 00, 01, 02, 03, 04, 05, 06, 07, 08, 09, 0A, 0B...0Z, followed by 10-12, 20-2Z, etc.

\author{
Amarasinghe, Priyanthi M., OM \\ Aoki, T., OR \\ Babu, Sachidananda, 09 \\ Badano, G., $\mathrm{OH}$ \\ Bos, Philip, 06 \\ Boulade, $\mathrm{O}$., $\mathrm{OH}$ \\ Brabec, Christoph J., OK \\ Buerhop, Claudia, OK \\ Cai, Guixia, OS \\ Calvano, Nicholas, OD \\ Camacho-López, Santiago, OL \\ Camus, Christian, OK \\ Cardimona, D. A., 03 \\ Cervera, C., $\mathrm{OH}$ \\ Chang, Chein-I, ON \\ Chen, Nanjun, 04 \\ Choi, K. K., 05 \\ Cosío-León, María, OL \\ Diestler, Mark, OM \\ Doll, Bernd, OK \\ Dong, Liang, OF \\ D'Souza, A. I., OE \\ Dupuis, Russell D., 09 \\ Efstathiadis, Harry, 09, 01 \\ Estrada-Garcia, H. J., OP \\ Estrada-Pintor, M. I., OP \\ Estudillo-Ayala, J. M., OP \\ Feng, Jerry, OM \\ Fièque, $\mathrm{B} ., \mathrm{OH}$ \\ Fu, R. X., 05 \\ Gallegos-Arellano, E., OP \\ Gao, Fei, 03, 04 \\ Gao, Qingsong, 0T \\ Ghuman, Parminder, 09 \\ Gnatyuk, V. A., OR \\ Gómez, Claudia M., OL \\ Gomółka, E., 07 \\ Gravrand, $\mathrm{O}$., $\mathrm{OH}$ \\ Gu, Guohua, OT \\ Gumbs, G., 03 \\ Gupta, Neelam, OM \\ Haskovic, Emir Y., ON \\ Hauch, Jens, OK \\ Heller, Eric R., 04 \\ Huang, Danhong, 03, 04 \\ Iurov, A., 03 \\ Jauregui-Vazquez, D., OP \\ Jensen, James, OM \\ Jensen, Janet L., OM
}

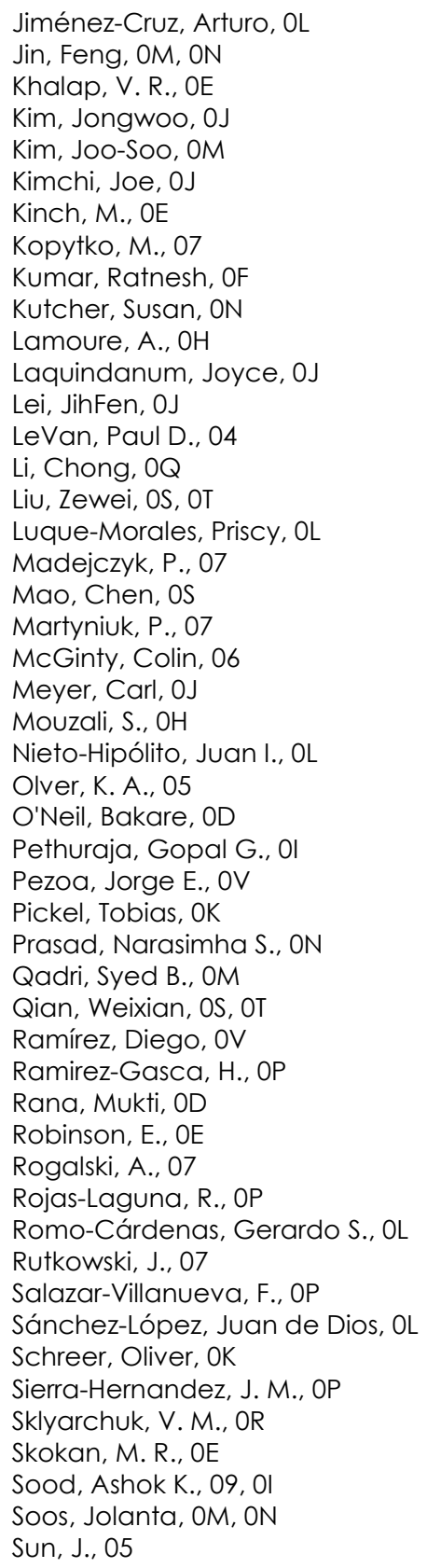


Tabassum, Shawana, OF

Teubner, Janine, OK

Trivedi, Sudhir B., OM, ON

Vázquez Briseño, Mabel, OL

Welser, Roger E., Ol

Wijewarnasuriya, Priyalal S., 0

Xue, Bai, ON

Yang, Jinqing, OS, OT

Yuan, Henry, OJ

Zeller, John W., 09, 이

Zetzmann, Cornelia, OK

Zhang, Jiawen, OJ

Zhang, Jun, OS, OT

Zhang, Yi, OQ

Zhuang, Zhi, OQ

Proc. of SPIE Vol. 10766 1076601-6

Downloaded From: https://www.spiedigitallibrary.org/conference-proceedings-of-spie on 26 Apr 2023 Terms of Use: https://www.spiedigitallibrary.org/terms-of-use 


\title{
Conference Committee
}

\author{
Program Track Chair
}

Allen H.-L. Huang, University of Wisconsin-Madison (United States)

Conference Chairs

Paul D. LeVan, Air Force Research Laboratory (United States)

Priyalal Wijewarnasuriya, U.S. Army Research Laboratory (United States)

Arvind I. D'Souza, Leonardo DRS (United States)

Conference Program Committee

Sachidananda R. Babu, NASA Earth Science Technology Office (United States)

Enrico Bellotti, Boston University (United States)

Vincent M. Cowan, Air Force Research Laboratory (United States)

Eric A. DeCuir Jr., U.S. Army Research Laboratory (United States)

Eustace L. Dereniak, College of Optical Sciences, The University of Arizona (United States)

Nibir K. Dhar, U.S. Army Night Vision \& Electronic Sensors Directorate (United States)

Sarath D. Gunapala, Jet Propulsion Laboratory (United States)

Sanjay Krishna, Center for High Technology Materials (United States)

Jay S. Lewis, Defense Advanced Research Projects Agency (United States)

Hooman Mohseni, Northwestern University (United States)

Hiroshi Murakami, Japan Aerospace Exploration Agency (Japan)

Ünal Sakoglu, University of Houston-Clear Lake (United States)

Ashok K. Sood, Magnolia Optical Technologies, Inc. (United States)

Session Chairs

1 IR Sensors, Devices, and Applications: Detector Theory, Models, and Simulations

Arvind I. D'Souza, Leonardo DRS (United States)

Paul D. LeVan, Air Force Research Laboratory (United States)

2 Novel Detectors and Materials

Priyalal Wijewarnasuriya, U.S. Army Research Laboratory (United States)

Arvind I. D'Souza, Leonardo DRS (United States) 
3 Characterization and Novel Pixel Processing

Ashok K. Sood, Magnolia Optical Technologies, Inc. (United States)

Paul D. LeVan, Air Force Research Laboratory (United States)

4 Focal Plane Arrays

Arvind I. D'Souza, Leonardo DRS (United States)

Sachidananda R. Babu, NASA Earth Science Technology Office (United States)

5 EO/IR Components and Applications

Paul D. LeVan, Air Force Research Laboratory (United States)

Sachidananda R. Babu, NASA Earth Science Technology Office (United States)

6 Innovative EO Fiber Applications

Priyalal Wijewarnasuriya, U.S. Army Research Laboratory (United States)

Ashok K. Sood, Magnolia Optical Technologies, Inc. (United States) 


\title{
Introduction
}

\author{
Innovations in remote sensing sensors (Invited Paper) \\ Sachidananda R. Babu, NASA Earth Science Technology Office \\ (United States)
}

Dr. Babu described NASA ESTO, its recent emphasis on small and cube satellites for accomplishing the Earth observing missions, and some of the potential game changers. Higher levels of risk now accepted, especially for new emphasis on smaller payloads. The emphasis on smaller payloads (Weather radar example) and a spectral radiometer made possible with an innovative NiP bolometer highlighted the emphasis on TRL progression. The progression of dispersive spectrometers is another good example, with package dimensions now measured in $\mathrm{mm}$ for smaller aperture, lower spectral resolution applications. These truly tiny dispersive spectrometers showcase the thrust to minimize sensor hardware SWAP. Novel sensor array technologies are underway, perhaps impacting the commercial market as well. How to measure infusion of the developed technologies? The rate of increase of their technology readiness levels. One of the noted principal investigator concerns has been maintaining an emphasis on well-calibrated data, which traditional NASA earth imagers achieved with sophisticated, on-board calibration equipment. These needs are now being met with a larger network of calibrated Earth scenes.

\section{Microscopic theory for point-defect effects on photon absorption in quantum-well systems}

Danhong Huang, Air Force Research Lab. (United States); Andrii lurov, The Univ. of New Mexico (United States); Fei Gao, Univ. of Michigan (United States); Godfrey Gumbs, Hunter College (United States); David Cardimona, Air Force Research Lab. (United States)

Dr. Huang focused on the optical absorption changes with high energy, charged particle damage to detector structures, in this case Quantum Well (QW). In the context of GaAs, he described polarizability components as key physical elements that are fundamental to the "parameter free" model that he described. With two sub-levels per QW, a "recombination offset" is included in the diffusion equation by accounting for the dispersal of vacancies and interstitials by the primary knockout atom. The full theoretical formalism accounts for defect formation and migration, recombinations, and changes in optical properties. 


\section{Atomic-level based non-ionizing energy loss: an application to GaAs and GaN semiconductor materials}

Fei Gao, Nanjun Chen, Univ. of Michigan (United States); Danhong Huang, Eric R. Heller, Paul D. LeVan, Air Force Research Lab. (United States)

Fei Gao described NIEL (Non-lonizing Energy Loss) for a GaAs and GaN comparison. He began by noting that charged particle damage measurements are expensive, sometimes being performed with the sample at cryogenic temperatures, so there is a place for high confidence modeling to supplement or eliminate some of the testing. Relieving the need to perform some of the radiation energy or dosage step measurements would be of benefit. A simplified Molecular Dynamics explanation was provided by comparisons with a solution of Newton's equation per atom. Nice comparisons were given for 2, 5, and $20 \mathrm{keV}$ proton energies. Interestingly, GaN begins with more initial displaced atoms than GaAs, but the recombination properties are very different, and the overall result is less displacement damage in GaN after diffusion and recombinations. As the next material slated for study is InAs.

\section{A systematic study of resonator quantum well infrared photodetector (QWIP)} Jason N. Sun, Kwong Choi, Kimberley Olver, Richard Fu, U.S. Army Research Lab. (United States)

The RQWIP resonator architecture involves major change of incident angle after entry into the QW structure, allowing for preferential absorption along the directions favored by the QW. Six samples with varying number of QWs (10 \& 23) QWs, and three values of doping density, were considered in this study. The alignment tolerance on the diffractive elements is very fine, and challenges were met. A very detailed explanation of the processing steps followed. Before and after pictures of substrate removal clearly expose the resonator structure in a microscopic photo. Very noteworthy values of QE were found for several of the test structures. NETD is also noteworthy, when these LWIR photodetectors are operated at slightly below liquid nitrogen temperature.

\section{Sensitive uncooled thermal imager based on liquid crystal Fabry-Perot interferometer \\ Colin P. McGinty, Liquid Crystal Institute (United States); Robert K. Reich, Harry R. Clark, Valerie A. Finnemeyer, Shaun R. Berry, MIT Lincoln Lab. (United States); Philip J. Bos, Liquid Crystal Institute (United States) \\ C. McGinty's Liquid Crystal bolometer was motivated by first describing it in comparison with the standard, thermally isolated microbolometer structures. In his case, the temperature sensitive parameter is transmission, as measured by a background laser. Various thicknesses of the liquid crystal film were considered.}


The approach was also noted to accommodate a differential measurement, if a polarization rotator could be included with two laser wavelengths. A dramatic increase of the temperature coefficient of transmission was noted for his approach compared with previous embodiment of this technical approach, as described in 2016 SPIE proceedings by a different group.

\section{High-operating temperatures InAsSb/AISb heterostructure infrared detectors}

Małgorzata Kopyłko, Emilia Gomółka, Piołr Martyniuk, Pawel Madejczyk, Jaroslaw Rutkowski, Antoni Rogalski, Wojskowa Akademia Techniczna im. Jaroslawa Dabrowskiego (Poland)

Dr. Kopytko described effects of optical immersion of heterostructures in terms of D* sensitivity figure of merit under higher operating temperature conditions, and under the assumption of Johnson-noise limited performance. Results compare favorably with commercial devices from Hamamatsu. Activation energies were determined and found close to bandgap energy for the $\mathrm{n}$ absorber region, but only one-half of the bandgap in p regions, presumably due to higher ShockleyRead-Hall currents. Assessments were made of levels of surface leakage currents. An interesting comparison was made over a wide range of wavelengths with "Rule 07" HgCdTe results. In response to a question on backside illumination, this illumination geometry was confirmed. A follow-on question asked if the $\times 10$ improvement with immersion could also be realized for HgCdTe, which is also grown on GaAs substrates in the Dr. Kopytko's case.

\section{Strain-compensated GalnSb/AIGalnSb type-I MQW for $\mathrm{CO}_{2}$ detection}

Manuel Reza, Matthew Steer, Univ. of Glasgow (United Kingdom); Calum MacGregor, Gas Sensing Solutions Ltd. (United Kingdom); lain Thayne, Marc Sorel, Univ. of Glasgow (United Kingdom)

M. Reza showed $\mathrm{CO}_{2}$ gas absorption spectrum (3 to 5 micron region), a wavelength range preferred as it is devoid of significant water absorption features. An LED approach for illumination appears to be the better SWAP choice for this $\mathrm{CO}_{2}$ gas detection application, at a wavelength near 4.2 micron. Compressive strain was found to introduce band curvature, and acts as a tradeoff with the number of QWs to optimize performance. A very interesting approach was described for the introduction of purposeful misfit at growth interface leading to improved performance. In response to audience question, operation of the device is planned at room temperature.

\section{Development of high performance ultraviolet and near-infrared detector technologies}

Ashok K. Sood, John W. Zeller, Magnolia Optical Technologies, Inc. (United States);

Parminder Ghuman, NASA Goddard Space Flight Ctr. (United States); 
Sachidananda R. Babu, NASA Earth Science Technology Office (United States); Nibir K. Dhar, U.S. Army Night Vision \& Electronic Sensors Directorate (United States); Priyalal Wijewarnasuriya, U.S. Army Research Lab. (United States)

John Zeller described two technologies, the first being Ge detectors grown on very large Si substrates for Visible and NIR detection, and secondly GaN/AIGaN for UV detection. Progressively increased amounts of Ga were noted to achieve shorter wavelength detection in UV. Curves of current vs voltage were shown for a variety of conditions, and responsivities in Amps per Watt of incident radiation were provided. Large avalanche gains were noted. In response to question on excess noise factor, it was noted that this is perhaps irrelevant to the Geiger mode in which the detector is employed. A question on the use of a sacrificial layer of oxide as part of fabrication process was asked, and answered in detail.

\section{Facets of imaging technology: A perspective into the future (Invited Paper)}

Nibir K. Dhar, U.S. Army Night Vision \& Electronic Sensors Directorate (United States)

Dr Dhar proved an overview of NVESD and his S\&T organization in particular. The NVESD focus areas (e.g., ISR, RSTA) and unique facilities were described, as well as how these are supported by the S\&T office. Electro-Optical spectrum interests extend from UV to Radar. The speaker motivated imaging technology needs by showing a graphic with increase in intelligence on one axis, and increased resolution towards "visual cortex" capability on the other. The Plenoptic character of light is to be maximally exploited to render the greatest scene information. The fundamental challenges of large (GPix) cameras in terms of aberration limits were described in the context of Lohmann's publication in 1989. Impressive images of large outdoor scenes that supported very fine zoom details were noteworthy. Other thrust areas include smaller pixel pitches, and sensor array extension into the third dimension, in some cases with MEMS capacitors, to accommodate increased charge integration needs. Other truly novel areas were described: the tradeoff of high-resolution vs camera frame rate; integral imaging as a potential means to suppress Poisson noise; sensing with compression as opposed to the nominal collection of large amounts of data followed by data compression. Machine Learning has shown promise in such areas as transforming an infrared image of person into a faithful visual image. Fusion of Visible, MWIR, and LWIR continues to reveal greater detection prowess than any waveband taken separately. Questions included sensor array formats and pixel pitches, with 4K $x$ 4K on 6 um pitch noted as now achievable. In addition, can different wavebands be combined with different perspectives to exploit overall plenoptic capabilities?

\section{Real-time infrared image deblurring using FPGA-based solution for air vehicles}

No presentation given. 


\section{Research on the stability of CTIA readout circuit for IR Detector}

No presentation given.

\section{Electrical and optical characterization of AlxNy thin films}

Nicholas P. Calvano, Bakare O'Neil, Mukti Rana, Delaware State Univ. (United States)

Nicholas Calvano motivated this discussion of thin films of aluminum nitride with Planck radiation distribution for room-temperature radiation. He described various detection technologies (including pyro mechanism relevant to his presentation). Key to realizing this capability was the reduction of molecular oxygen during fabrication process, leading to increases in $\mathrm{Al}$ and $\mathrm{N}$ in the sample. Fabrication temperatures and times were also varied in this study. Grown samples were fully characterized with x-ray diffraction. Overall improvement of temperature coefficient of transmission was found.

High operating temperature MCT discrete detector data and analysis Ernest Robinson, Vaikunth Khalap, Arvind I. D'Souza, Michael A. Kinch, Mark Skokan, Leonardo DRS (United States)

Dr. Robinson described HDVIP IR detectors with cutoff wavelengths near 5 um at $240 \mathrm{~K}$ operating temperature. A panel of test structures was fabricated with varying acceptor doping, for both 6 and $8 \mathrm{um}$ via diameters. Very careful $1 / \mathrm{f}$ noise measurements were made over a broad range of frequencies. Interestingly, noise was dominant on the $\mathrm{n}$-side and dark current dominated on the $\mathrm{p}$-side. Diffusioncurrent-limited performance was achieved between 120 and 280 Kelvin.

\section{Tunable mid-infrared optical resonator on nanopatterned chalcogenide glasses}

Shawana Tabassum, lowa State Univ of Science and Technology (United States); Liang Dong, Ratnesh Kumar, lowa State Univ. of Science and Technology (United States)

S. Tabussun described an optical resonator concept for the detection of gases emitted by stressed plants as a means of identifying this condition. Both ethylene and methanol have absorption features in the 2.5 to 2.6 micron region, such that an optical resonator tuned to these wavelengths can be used as a means of gas detection and concentration estimates. Detailed sensor fabrication steps were described, including the fabrication of nanoposts and the eventual achievement of complete solvent droplet removal. Use of the 2-D grating equation, modified in a way to account for post geometry, can now successfully predict the detection wavelengths for a given design. 


\section{Material and process development for high operating temperature LWIR PIN HgCdTe focal plane arrays}

Silviu Velicu, EPIR Technologies, Inc. (United States)

S. Velicu provided a very comprehensive overview of this PIN detector architecture emphasizing its strongly depleted absorber layer. Emphasis was placed on achieving optimal performance in the "HOT" operating temperature regime. This detector architecture, involving arsenic implants for junction formation, was examined in terms of reducing potential implant damage. A separate part of the strategy involved identification and removal of background metal impurities; the latter was achieved with careful use of gettering layers followed by anneals. Finally, tuning of the $\mathrm{Hg}$ partial pressure was found helpful in controlling $\mathrm{Hg}$ vacancies. Overall, efforts have been rewarded with noteworthy levels of performance, with the new results comparing very favorably with the existing EPIR database.

\section{Status of the development of $2 k^{2}$ IR FPAs for astronomy and space in Europe}

Giacomo Badano, Cyril Cervera, Olivier Gravrand, CEA-LETI (France); Bruno Fièque, Adrien Lamoure, SOFRADIR (France); Olivier Boulade, Salima Mouzali, CEADAP (France)

G. Badano described the quest for large format $(2 K \times 2 K)$ SWIR arrays with performance requirements levied for the 0.8 to 2.1 micron range. These detectors are grown on large area CdZnTe substrates and with liquid phase epitaxy (although comparison with MBE grown detectors was possible, given availability of this material source as well). Very low values of dark current (at $100 \mathrm{~K}$ ) were measurable once issues with an earlier generation of read-out circuit (ROIC) thermal glow were overcome with new ROIC designs. Results of evaluation against high energy proton dosing help evaluate the promise of the technology for use in space.

\section{Nanostructured antireflection coatings for infrared sensors and applications}

Ashok K. Sood, Gopal G. Pethuraja, John W. Zeller, Roger E. Welser, Magnolia Optical Technologies, Inc. (United States); Nibir K. Dhar, U.S. Army Night Vision \& Electronic Sensors Directorate (United States); Priyalal Wijewarnasuriya, U.S. Army Research Lab. (United States); Harry Efstathiadis, SUNY Polytechnic Institute (United States)

Gopal Pethuraja described new developments, for baffle and screen applications, of anti-reflection coatings in the form of $\mathrm{C}$-nanotubes that are deposited along preferred lines of orientation. These coatings show efficacy both over a broad range of wavelengths and for light arriving at multiple angles of incidence. 
Refractive index grading was also shown possible with changes in the properties of layered C-nanotubes.

\section{High performance SWIR HgCdTe $320 \times 256 / 30 \mu \mathrm{m}$ FPAs at Teledyne Judson Technologies}

Henry Yuan, Jiawen Zhang, Jongwoo Kim, Carl Meyer, Joyce Laquindanum, Joseph Kimchi, JihFen Lei, Teledyne Judson Technologies (United States)

Henry Yuan described HgCdTe production FPAs, with 2.5 and 2.9 cutoff wavelengths. These FPAs are, packaged with cryocooler options allowing operation at temperatures of 23C, 5C, -70C and near liquid nitrogen temperature, for progressively lower levels of dark current. This pixel architecture involves mesa formation via wet etching. Sensitivity histograms were shown to assess pixel operability, and comparisons of dark current (actually total pixel current for low dark current and FOV-limited conditions resulting from cold shielding limitations) with Rule 07 are very favorable, and in some cases below the Rule 07 state-of theart, in terms of dark current.

High throughput, outdoor characterization of silicon photovoltaic modules by moving electroluminescence measurements

Bernd Doll, Bayerisches Zentrum für Angewandte Energieforschung e.V. (Germany), Erlangen Graduate School in Advanced Optical Technologies (Germany); Tobias Pickel, Bayerisches Zentrum für Angewandte Energieforschung e.V. (Germany); Oliver Schreer, IRCAM GmbH (Germany); Cornelia Zetzmann, Rauschert GmbH (Germany); Janine Teubner, Claudia Buerhop, Jens Hauch, Christian Camus, Bayerisches Zentrum für Angewandte Energieforschung e.V. (Germany); Christoph J. Brabec, Bayerisches Zentrum für Angewandte Energieforschung e.V. (Germany), Friedrich-Alexander-Univ. Erlangen-Nürnberg (Germany)

In order to inspect remotely the quality of cells in photovoltaic plants, electroluminescence measurements were studied. These were shown to reveal crack and "grid finder" defects that could then be correlated with diminished electrical performance. Various cell types were examined, including HIT Silicon, poly-silicon, and mono-crystalline types. Once proven with hand-help inspection equipment working over distances of 5 to 6 meters, the technological approach might be practical for inspections from aerial platforms.

\section{Study on mid-IR spectroscopy on whole blood samples for human glucose quantification applications}

Gerardo Salvador Romo-Cárdenas, Juan de Dios Sánchez-López, Maria CosioLeón, Priscy Luque-Morales, Claudia M. Gómez-Gutierrez, Juan I. Nieto-Hipolito, Arturo Jiménez-Cruz, Univ. Autónoma de Baja California (Mexico); Santiago 
Camacho-López, Ctr. de Investigación Científica y de Educación Superior de Ensenada B.C. (Mexico); Mabel Váquez-Briseño, Univ. Autónoma de Baja California (Mexico)

G. Romo-Cardenas considered the thermal infrared (10-micron region) for blood insulin and glucose monitoring, and began with an explanation of the interdisciplinary (Physics and medicine) nature of the work. Type 1 and 2 diabetes properties were reviewed, in order to motivate this work. The spectra of both insulin and glucose are strong functions of concentration in the 10-micron region. Methods for separating the relative amounts of the two substances were found, seeming to enable a protocol for biomedical optical sensing of these important constituents.

\section{Anomalous thermal expansion of mercurous halides}

Priyanthi Amarasinghe, JooSoo Kim, Feng Jin, Sudhir Trivedi, Brimrose Technology Corp. (United States); Syed Qadri, Jerry Feng, U.S. Naval Research Lab. (United States); Jolanta Soos, Mark Diestler, Brimrose Technology Corp. (United States); Neelam Guptha, U.S. Army Research Lab. (United States); Janet Jensen, James Jensen, U.S. Army Edgewood Chemical Biological Ctr. (United States)

P. Amarasinghe described mercurous halides include $\mathrm{Hg}_{2} \mathrm{Cl}_{2}, \mathrm{Hg}_{2} \mathrm{Br}_{2} \mathrm{Hg}_{2} \mathrm{I}_{2}$, and noted that the first-ever growth of larger crystals of two of these three has been achieved for their promising acousto-optical capabilities over wavelengths extending out to 40 microns. Growth procedures were carefully described. Crystal characterizations were followed by study of thermal properties that include thermal expansion values that differ for different orientations within the crystal. Among other interesting properties, these crystals display negative refractive index, simulating properties of the artificial metamaterials grown specifically to achieve a negative index.

\section{Polarimetric hyperspectral imaging with acousto-optic tunable filter in the visible to shortwave infrared range}

Feng Jin, Emir Y. Haskovic, Sudhir Trivedi, Jolanta Soos, Brimrose Corp. of America (United States); Narasimha S. Prasad, NASA Langley Research Ctr. (United States)

The second Brimrose presentation, by Feng Jin, then described a specific Acoustooptical tunable filter (AOTF) for use in an imaging spectro-polarimeter over the range of wavelengths from 0.35 to 4.5 microns. (Brightness variation with wavelength among different cloud types suggest that cloud properties can be distinguished in images taken with such a device, against a sky background.) 


\section{Flexible mid-Infrared photonic chip for label-free and real-time biochemical sensing}

No presentation given.

\section{Design of a Fabry-Perot interferometer based on silicon wafer for dielectric gas sensing applications}

Marco Estrada, Univ. de Guanajuato (Mexico); Eloisa Gallegos-Arellano, Univ. Tecnológica de Salamanca (Mexico); J. M. Sierra-Hernandez, D. JaureguiVazquez, J. M. Estudillo-Ayala, Univ. de Guanajuato (Mexico); F. SalazarVillanueva, Univ. Tecnológica de Salamanca (Mexico); H. Ramirez-Gasca, H. J. Estrada, Roberto Rojas-Laguna, Univ. de Guanajuato (Mexico)

M. Estrada Pintar employed Fabry-Perot (FP) interferometry for sulphur hexafluoride gas detection in the context of high voltage electrical equipment. Properties of the FP equation for various values of etalon reflectivity were modeled, and can be exploited to match optimally properties of the gas absorption features that are to be detected. Further wavelength tuning can be achieved by varying the angle of incidence of the incoming beam used as a background source to illuminate the detector through the intervening gas.

\section{Fiber optic transverse pressure detection technology for structural health monitoring}

Yi Zhang, Zhi Zhuang, Chong Li, China Academy of Engineering Physics (China)

Traditional stress sensors are limited for use in smaller spaces, so compactness in the structural health monitoring field suggests the employment of sensors embedded within the structure or material as an attractive option. An embedded fiber optic sensor based on the photonic crystal fiber measures the transverse stress for structural health monitoring. This pressure sensor has a small diameter (235 micron) and a preferred direction for sensitivity. Traditional calibration methods would result in a large calibration error, so a high precision calibration device $(0.1 \%$ full scale) has been designed to resolve the calibration problem. The resulting correlation between the wavelength shift in a Sagnac loop and pressure was found linear in terms of displacement per force measured.

Paul D. LeVan

Priyalal Wijewarnasuriya Arvind I. D'Souza 
Proc. of SPIE Vol. 10766 1076601-18

Downloaded From: https://www.spiedigitallibrary.org/conference-proceedings-of-spie on 26 Apr 2023 Terms of Use: https://www.spiedigitallibrary.org/terms-of-use 